\title{
Transition towards Energy Efficiency: Developing the Nigerian Building Energy Efficiency Code
}

\author{
Susanne Geissler ${ }^{1}$, Doris Österreicher ${ }^{2, *(1)}$ and Ene Macharm ${ }^{3}$ \\ 1 SERA energy \& resources e.U., 1070 Vienna, Austria; susanne.geissler@sustain.at \\ 2 Department of Civil Engineering and Natural Hazards, Institute of Structural Engineering, \\ Working Group Sustainable Constructions, University of Natural Resources and Life Sciences, \\ 1190 Vienna, Austria \\ 3 Deutsche Gesellschaft für Internationale Zusammenarbeit (GIZ) GmbH, 53113 Bonn, Germany; \\ ene.macharm@giz.de \\ * Correspondence: doris.oesterreicher@boku.ac.at; Tel.: +43-1-47654-87531
}

Received: 1 June 2018; Accepted: 20 July 2018; Published: 26 July 2018

\begin{abstract}
In Nigeria, there is an estimated deficit of 17 million housing units. Power supply is insufficient, and the electricity supply for about 60 million Nigerians relies on private generators, causing noise, pollution, and high expenditures for mainly imported fuel. Altogether, current challenges clearly demonstrate the need for effective energy efficiency policies targeting also the building sector. The Nigerian Energy Support Program began in 2013, among others, with the objective being to support the Nigerian Government in developing the Nigerian Building Energy Efficiency Code. This paper presents two preparatory activities carried out in order to come up with suggestions for a legal framework well suited for the situation on the ground: the Case Study Building Analysis carried out in collaboration with a Nigerian developer and the Nigerian Building Energy Efficiency Guideline, elaborated together with stakeholders. The results of preparatory activities pointed out that the code must put emphasis on climate adaptive design and must define requirements and procedures in a clear and simple way to allow for effective enforcement. Only then can energy-efficient mass housing be feasible in Nigeria. The paper concludes with a description of the Nigerian Building Energy Efficiency Code (BEEC), officially approved and launched by the Federal Minister of Power, Works and Housing on 29 August 2017.
\end{abstract}

Keywords: affordable housing; climate adaptive design; energy building code; energy transition; stakeholder engagement; policy pathways; developing countries; tropical regions

\section{Introduction}

This paper describes the policy pathway towards increasing the energy efficiency of the Nigerian building sector. The core element is the development and implementation of a new legal framework addressing the energy efficiency in buildings, namely the Nigerian Building Energy Efficiency Code (BEEC). The code development is based in particular on two main results of stakeholder involvement activities providing the basis for BEEC development: The Nigerian Building Energy Efficiency Guideline (BEEG), and a case study carried out in collaboration with a Nigerian developer. Activities were carried out as part of the Nigerian Energy Support Program (NESP), a five-year working program (2013-2018), implemented by Deutsche Gesellschaft für Internationale Zusammenarbeit (GIZ) GmbH in collaboration with the Federal Ministry of Power Works and Housing (FMPWH), and funded by the German Government and the European Union.

The paper first outlines basic information about the Nigerian building sector, in order to better understand the challenges of code development. The BEEG is described, aiming at creating awareness 
for the need for energy efficiency among stakeholders, and a common understanding on the challenges and possible solutions. Discussions with stakeholders in preparation of the BEEG as well as the development of the BEEG made it clear that climate adaptive design is the key to reducing electricity consumption for cooling in a cost-efficient way. In order to learn more about the gap between current design practice and climate adaptive design, a demonstration project was started together with a Nigerian developer, aiming at improving standard designs with various energy efficiency measures including renewable energy systems. Both activities, the BEEG development and the case study analysis, helped to shape the requirements for developing the Nigerian BEEC. The actual code as approved and launched by the Federal Minister of Power, Works and Housing on 29 August 2017 is also described, complemented by a discussion of and conclusions on the material presented.

\subsection{Status Quo: Overview of the Nigerian Building Sector}

\subsubsection{Responsible Authorities and Legal Framework}

The Federal Ministry of Power, Works and Housing (Housing Sector) is the umbrella policy arm of the Federal Nigerian Government charged with the responsibility of ensuring adequate and sustainable housing delivery and maintenance of a conducive living environment that meets the needs and aspirations of the Nigerian citizens. The Ministry's mission is to facilitate the provision of adequate and affordable housing for all Nigerians, in both the urban and rural areas, in a secure, healthy and decent environment.

Key functions of the Ministry, which have been consolidated over time, include the following:

- Formulating policies and setting standards;

- Monitoring the implementation of policies and enforcing compliance with codes, regulations and standards;

- Providing, upgrading and maintaining infrastructure for the housing stock, including public buildings of Federal Ministries.

The National Building Code provided by the Federal Government is a set of rules, currently mainly referring to the structural system, general safety, and fire safety, without specific requirements regarding energy efficiency and renewable energy use. Because the code can only be mandatory for the buildings owned by the Federal Government, it is pertinent that the code is domesticated in the various states of the federation, in order to create an effective regulatory framework for implementation and enforcement at the local level. In urban areas, the building codes and building permit procedures are relevant, except small buildings defined by building area or by building volume, while building legislation is practically non-existent in rural areas.

However, the absence of powerful enforcement mechanism has been a major drawback to the effective operation of legislation in general, and notably in the building sector [1].

In the context of the building code, the Nigerian Urban and Regional Planning Law, (NURPL) Decree No. 88 of 15 December 1992 is essential because it guides the policies for urban planning and development in the Nigerian states. Among others, designated authorities are required to prepare and implement the following instruments of spatial development: town plan, rural area plan, local plan, and subject plan, and the control of development within their area of jurisdiction. NURPL provides the regulation of aspects such as the height of buildings and distance between buildings, building orientation, air movement, and public green spaces. Thus, provisions can either hinder or support energy efficiency at the building level, as well as renewable energy use. Currently, business-as-usual procedures do not take these aspects into account.

NURPL also provides for the establishment of a department known as the Development Control Department. It gives the planning bodies the power to approve building permit applications with amendment, or reject applications completely. 


\subsubsection{Energy Supply of Buildings}

In Nigeria, affordable electricity supply is neither sufficient nor reliable, and the gap between the demand for and supply of energy is deepening. The Nigerian Energy Sector Study illustrates the urgent need for energy efficiency policies as a partial remedy to the problem [2]: According to the Nigerian Electricity Regulatory Commission (NERC) statistics, $80 \%$ of actual generation capacity in 2015 comes from gas-based power plants, while the remaining energy comes from hydro power plants. For installed capacity the ratio is $84 \%$ from gas and $16 \%$ from hydro power plants. The existing fleet of power plants is a mix of plants built before the 1990s and plants built (or being built) since the mid-1990s. Since the older thermal power stations suffer considerably from poor maintenance, the available generating capacity was just under $6200 \mathrm{MW}$ in 2012 and has risen to only $6840 \mathrm{MW}$ in 2015. However, unavailability of gas and water shortage severely limits the power plant performance, and grid constraints seriously affect security of electricity supply. Estimated peak demand is about $12,800 \mathrm{MW}$, while peak generation is at best about $5000 \mathrm{MW}$, and the only way this extreme shortfall can be made up is by relying on off-grid generation. According to a 2013 survey, approximately $80 \%$ of Nigerians use alternate sources of electricity supply, such as generators or solar inverters. Estimates suggest that between 8 and $14 \mathrm{GW}$ of decentralized generator capacity (diesel and petrol) is currently installed in the country. Furthermore it is estimated that $86 \%$ of the companies in Nigeria own or share a generator with $48 \%$ of their total electricity demand being covered by these private generators. With several millions of privately installed diesel generators, Nigeria leads Africa as a generator importer and is one of the highest importers worldwide, with the total annual import figure being NGN 17.9 billion (US\$ 112 million) [2].

However, this method of electricity generation is certainly problematic, not only because of the evident negative impact on people's health as a consequence of permanent air pollution and noise, but also because of lack of reliability regarding fuel supply. Although Nigeria is ranked as the largest African OPEC crude oil producer, its capacity in refineries is very small, and the major share of petrol and diesel must be imported [3]. Extreme fluctuation in oil prices, for example from US\$147 in July 2008 to below US $\$ 45$ by December 2008, and from US $\$ 115$ in the second quarter of 2014 to below US\$30 as of January 2016, have heavily affected Nigeria's budget, because an average of $80 \%$ of government revenue depends on oil exports. In addition, pipeline violations as a consequence of the independence movement of the Delta region have negatively impacted on production capacity $[4,5]$. As a consequence, fuel subsidies have been under review and attempts were made to cut them. However, this caused the doubling of prices and, as a result, alarming social unrest [6].

The above said clearly explains the motivation for developing and implementing energy efficiency policies in addition to strong efforts to improve the availability of affordable electricity, be it on-grid or off-grid supply. Tapping the full potential of energy efficiency definitely reduces energy demand and thus certainly relieves pressure from the energy supply sector.

\subsubsection{Current Building Practice and Characteristics of the Building Stock}

In Nigeria, an enormous effort in building construction is necessary to catch up with the estimated deficit of 17 million housing units. It is paramount to provide housing for the masses, but it is also clear that construction activities will certainly increase pressure on the existing energy supply system without effective policies targeting energy efficiency and decentralized utilization of renewable energy [2].

Despite fluctuating or even failing grid electricity supply and also fuel scarcity posing a problem with running own generators, there is the observation that new buildings are predominantly designed according to what is called an "international style of architecture". This design approach does not take into account the energy-related characteristics of the location of a building, but balances local conditions with the increased use of building services associated with an enormous amount of energy for air-conditioning and lighting, thereby increasing energy cost [7]. 
In Nigeria, there seems to be a general a lack of awareness about the direct link between building design and technologies, and their impact on energy efficiency in the state of the art building design. Traditional building materials and concepts responding to local climatic conditions are usually considered unprogressive, while modern materials and building designs from abroad are preferred, leading to designs that consume a large amount of energy, especially for cooling and lighting [1]. Even though there are a series of well-tested and advanced strategies available that would suit the climate (e.g., use of phase change materials, activation of thermal mass), these measures are not well established, as there is no local precedent available.

However, assessment of the status quo relies on experts' opinions, case study analyses, and general observations, because neither systematic data collection on the technical characteristics of the building stock is available, nor data about actual electricity consumption related to building types. There are even more challenges complicating the assessment of baseline information: the existence of suppressed energy demand (see Section 1.2), the practice of so-called estimated billing (households are charged based on estimations and not based on actual consumption due to absence of meters), electricity theft, and the fact that private generators take over in case of grid failure.

With regard to the utilization phase of residential buildings, Nigerians mostly rent or build houses, while the practice of buying houses is uncommon. Usually, rent is paid in advance for 12 or sometimes even for 24 months. Apart from difficulties in raising a substantial amount of money at a stretch, this practice also means that the owners will often not settle problems encountered in the buildings, since they have already been paid and therefore have no incentive to solve problems reported to them.

The summary of status quo presented above clearly shows that energy efficiency policies have to address the building sector in a way that initiates the necessary extensive paradigm shift towards energy saving design, construction, and utilization of buildings. However, it also demonstrates that the challenges are enormous, among others due to the severe lack of awareness among architects, engineers, builders, and clients, and due to the fact that reliable data is practically non-existent.

\subsection{Challenges for Policy Makers: Urbanization, Housing Deficit, Suppressed Electricity Demand}

The challenges described above are even enormously aggravated by rural-urban migration resulting in vast urbanization, which contributes to the huge housing deficit that Nigeria is facing. Urbanization leads to increased electricity consumption in buildings because of the development of the service sector on the one hand, and the increasing demand for energy services such as refrigeration, lighting, and cooling in the residential sector on the other hand.

In developing countries, people use approximately $50 \%$ of the total national electricity consumption in urban buildings. Currently, $40 \%$ of the African population (in total over 1 billion inhabitants) live in urban areas, and by 2050 this will increase to $60 \%$ (in total reaching the 2 billion mark) [8]. With a view to the situation in Nigeria, in 2015, the rural population has decreased to $52 \%$ compared to $85 \%$ in 1960 (percentage of total population), whereby the rural population refers to people living in rural areas as defined by national statistical offices [9]. With more than 190 million people in 2017, Nigeria is among the nine countries where half of the world's population growth is expected to be concentrated from 2017 to 2050 [10].

Relating population growth with the current average electricity consumption per capita and the UN Sustainable Development Goals reveals the major challenge regarding electricity supply: Indicators about energy consumption are very low compared to other countries. For Nigeria, the latest available indicator at a national level dating from 2015 is $140 \mathrm{kWh}$ electricity consumption per capita (not including privately generated electricity) according to the statistics of the International Energy Agency (IEA) [11]. This indicates that suppressed demand is huge, meaning that as soon as energy is available at affordable cost, people will use it to meet their demands, e.g., for domestic hot water preparation to improve hygienic standards, for cooking hot meals more than once per day, for consumption of electricity for ventilation, air-conditioning and lighting, or electronic devices. 
The fact that an increase in electricity consumption per capita will certainly be necessary, in order to achieve the UN Sustainable Development Goals, emphasizes the important role of energy efficiency policies in general, and especially thus addressing the building sector [12].

In view of the rapid population growth, the continuing rural-urban migration, and the expected increase in energy consumption, it is abundantly clear that energy efficiency potentials related with building designs must be exploited in order to reduce electricity demand for ventilation, air-conditioning, and lighting as much as possible. In this regard, the energy building code was identified as an important policy measure, provided that the code is suitable to be applied for mass housing.

\section{Methodology}

When the work for code development started, it was a clear requirement to avoid mistakes made in the past, namely taking legislation from other countries and adopting it without adequately adapting it to the true conditions concerning the technical, economic, and the societal environment, resulting in an ineffective legal framework. West African stakeholders consulted during the development of the concept note on energy efficiency in buildings as part of the SEEA-WA project under the lead of ECREEE (ECOWAS Centre for Renewable Energy and Energy Efficiency), the ECOWAS (Economic Community of West African States) Centre of Renewable Energy and Energy Efficiency, had certainly emphasized the importance of this problem [13]. Therefore, existing building codes should not only be reviewed to take into account lessons learnt elsewhere, but rather considerable attention had to be paid to the environment in which the code would be put into practice.

At the beginning of the work, existing energy efficiency building codes implemented in other countries were reviewed in order to benefit from their experiences and lessons learned. Several technical documents and reports on energy efficiency requirements, evaluation studies on implementation, compliance, and control were studied, among others [14-17], as well as documents available at the QUALICHeCK Platform [18], to mention only a few. They provided input for the discussion of possible approaches with stakeholders and served as a good basis to create a common understanding about the options on how to go about the development of an energy efficiency building code, which would be effective in practical application in the Nigerian environment.

Stakeholder discussions resulted in the conclusion that prior to launching the Nigerian Building Energy Efficiency Code (BEEC), information would be necessary in order to address the severe lack of awareness regarding energy efficiency in buildings in the professional environment. Thus, it was decided that the first Nigerian Building Energy Efficiency Guideline (BEEG) would be developed-structured along the main chapters of the future BEEC, but focusing on general information and guidance to achieve energy efficiency in the Nigerian building environment rather than presenting requirements, and to demonstrate its practical feasibility by implementing a pilot project together with a Nigerian developer.

Thus, building upon the review of existing codes and lessons learnt, two major preparatory activities were launched as an important basis for developing the actual energy efficiency building code, which are presented in more detail in this paper:

- The development of the Nigerian Building Energy Efficiency Guideline (BEEG);

- A demonstration project with a Nigerian developer.

Figure 1 summarizes the most important elements of code development and the time line of activities. The specification of contents of the BEEG and the actual development of the document as well as the demonstration project with the Nigerian developer, were carried out nearly in parallel, whereas the parametric study for defining minimum energy requirements and developing the labeling scheme built upon the lessons learnt from the two preparatory activities. They provided crucial information to define the scope of and the procedure for the parametric study. The parametric study was carried out within the period of one year (including stakeholder meetings and feedback loops). 


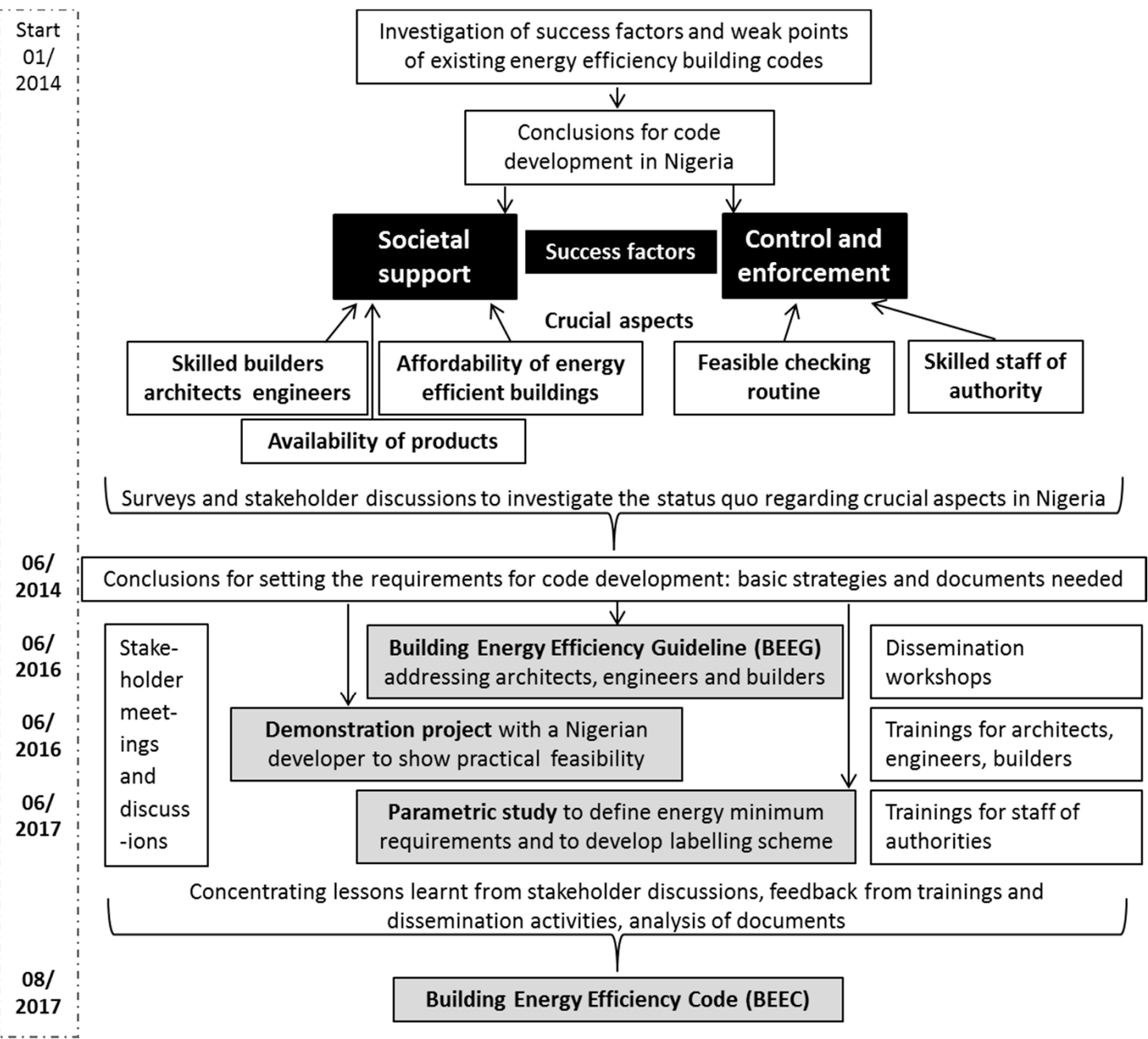

Figure 1. Overview of BEEC development.

\subsection{Preparatory Activity 1: Nigerian Building Energy Efficiency Guideline (BEEG)}

\subsubsection{Objectives and Content of the BEEG}

It was the objective to create awareness and acceptance of the new legislation to come in the form of an energy efficiency building code. Thus, stakeholder involvement was of paramount importance and was based on the establishment of a strong partnership with the Nigerian Federal Ministry of Power Works and Housing (Housing Sector) responsible for the energy efficiency building code.

It was agreed that the BEEG must certainly reflect the following topics representing the central elements of the new legislation at the same time:

- To fully exploit the potential of climate adaptive design as the most cost-effective energy efficiency measure;

- To consider the actual availability of energy-efficient products;

- To avoid or at least limit additional investment cost due to the need to make use of specific materials;

- To take into account the current qualification level of professionals and authority personnel, because professionals will have to comply with requirements, and authority personnel will have to check compliance. 


\subsubsection{Procedure of BEEG Development}

Development of the Guideline started in early 2015. A comprehensive stakeholder involvement process was initiated to include all relevant professional associations in developing the Guideline, and thus to ensure wide dissemination and application in practice. Reaching out to the relevant stakeholders and holding discussions with them was essential to capture the status quo regarding the qualification of staff designing and constructing buildings, as well as the qualification of staff approving the building permit and permit of use, the availability of building products on the Nigerian market, and the characteristics of the building stock, in order to define the requirements the future energy efficiency code named Nigerian Building Energy Efficiency Code (BEEC) should fulfill.

Group discussions, workshops, and personal interviews were conducted with representatives of the professional associations of architects, engineers, builders and developers, as well as with representatives of the building authority and other units of public administration. International experts substantially supported the elaboration of the Guideline by providing technical expertise.

\subsection{Preparatory Activity 2: Case Study Building Analysis}

\subsubsection{Conveying the Advantages of Climate Adaptive Design}

One of the key aspects of the second preparatory activity was to communicate and discuss the current building practice with local stakeholders involved in preparing the case study buildings. Within several workshops undertaken with the planning and development team of the case study, the following aspects were highlighted in order to present advantages of climate adaptive design.

The aspects and advantages of climate adaptive design have been widely covered in literature. One of the key aspects in this respect is to assess and learn from the vernacular architecture as described in great detail in [19] and more recently in [20]. The outer building shell, with its direct interaction with the climate, is especially of particular focus, as reviewed in depth in [21]. Schelbach further describes in [22] how the fundamental principles of climate adaptive architecture can be applied to modern buildings. The function of buildings is first and foremost to provide shelter, from external threats as well as climatic conditions. A thermally comfortable indoor environment is therefore a prerequisite in any design, however the term 'comfortable' depends on a series of external factors: personal conditions (e.g., young, old, healthy, ill), activities (e.g., sleeping, working, running), and clothing (e.g., light or heavy clothes). Influencing parameters on thermal comfort are usually temperature (room temperature, surface temperature, temperature differences), air quality (humidity, $\mathrm{CO}_{2}$ levels, oxygen levels, air velocity), and radiation (from systems, materials, or solar radiation).

The external climatic conditions obviously heavily influence the internal thermal conditions of a building; however, Heating, Ventilation and Air Conditioning (HVAC) systems can provide a defined indoor environment regardless of the building's architecture. Providing a stable $21^{\circ} \mathrm{C}$ indoor temperature even when the external air temperature is $35^{\circ} \mathrm{C}$ does not just result in exceptionally high cooling energy demands, but also provides unhealthy environments, where people step from a hot outdoor climate into a heavily cooled building. The more external factors such as climate, site, and use of the building, are therefore taken into account during planning, resulting in a climate adaptive building, the less (externally provided) energy the building will need in order to provide a comfortable indoor environment. The use and time of use of the building play in this context a significant role in the overall design: residential buildings are most heavily occupied during mornings, evenings, and nights, with usually less usage during daytime. Non-residential buildings, such as office buildings, are mostly used during daytime and are in addition characterized by heavier internal gains by people, machinery, and lighting. Solar gains must therefore be even more rigorously reduced in non-residential buildings to keep the cooling loads to a logical minimum. 
Climate-adaptive design takes advantage of the site without causing additional investment cost, for example by reducing the impact on energy demand for cooling by appropriate orientation, layout, and making use of natural ventilation. However, building orientation and also building layout are certainly influenced by urban planning. While climate adaptive architecture clearly relies on corresponding zoning plans regarding possible orientation, layout, height, and the like, standard designs, which disregard local conditions, do not consider the characteristics of the place influencing indoor air conditions, but use building service technologies and thus energy to deliver the requested comfort. Climate adaptive architecture is thus based on a detailed assessment of the overall climate as well as the local weather conditions such as daily and annual temperature, humidity curves, and radiation.

\subsubsection{Climatic Zones in Nigeria and Design Strategies}

In Nigeria, there is no data on official climate classification from a Nigerian institution as the agency responsible for this information. According to the Köppen-Geiger climate classification, Nigerian is divided into five zones, namely the tropical savanna climate (Aw), the hot semi-arid climate (BSh), the tropical monsoon climate (Am), the hot desert climate (BWh) and the tropical rainforest climate (Af) [23].

Similarly, Nigeria is located wholly within the tropical zone but shows significant climatic variations in different regions of the country. Two principal wind currents affect Nigeria. The Harmattan, from the northeast, is hot and dry and carries a reddish dust from the desert. The southwest wind brings cloudy and rainy weather. These conditions result in four climate types distinguishable as one moves from south to north. The climate is predominantly hot and dry in the north, with higher temperature and humidity swings, and it is hot and humid in the South, with fairly constant temperature and humidity levels. For the hot and humid climate, the seasons are not sharply defined, with constant temperatures throughout the year. Temperatures rarely exceed $32{ }^{\circ} \mathrm{C}$, but humidity is very high and nights are hot. The hot and dry climate exerts enormous influence on the country and has a very distinguishable rainy season and a dry season [24].

With a specific view on Abuja, the savannah climate predominant in the Abuja region is characterized by dry and wet seasons, constant high temperatures, low to moderate humidity levels, and limited temperature differences between day and night. Based on these characteristic conditions, one can deduct general architectural principles focusing particularly on cooling for these climatic regions. Shading and high performance glazing are important to reduce solar gains. External envelopes with low thermal transmittance can reduce heat losses, thus reducing the overall cooling load. Temperature regulative building materials and high thermal mass, which can store and release heat, ensure that heat generated during the daytime can be slowly discharged during cooler night times, even when temperature differences are not too high. Buildings, which are partly buried in the ground, can use the stable temperatures of the earth to balance peaks and variations in temperature. Wind towers or earth ducts can be applied to pre-cool buildings, however consideration must be given to the local micro-climate when using pre-cooling systems, as the effectiveness will strongly depend on local temperature and humidity ranges.

The design principles should follow the approach in first exploiting passive design measures, secondly in providing energy-efficient systems, and thirdly in applying renewable energy technology (see Figure 2). This logical approach will ensure that the architecture will play a significant role in the overall energy efficiency of the building, as it follows the requirement of the climate, site, and building use. To support the exploitation of the thermal characteristics of the building structure together with adequate use of building services and renewable energy systems, advanced thermal dynamic simulation models can be used to provide detailed design scenarios. 
The mass residential and utility buildings can particularly profit from intelligent and economical building design, which uses resources wisely, economically, and in a local context, as the principles of climate adaptive architecture can and should be applied to any building in order to provide adequate indoor thermal comfort in a highly efficient way under these challenging climatic conditions.

\subsubsection{Objectives and Procedure of the Case Study}

Discussions with Nigerian stakeholders made it clear that climate adaptive design is the key to reducing electricity consumption for cooling in a cost-efficient way. However, apart from studies about vernacular and historical architecture and model building simulations, there was insufficient information available on how to introduce climate adaptive design into current design approaches and how specific measures would affect investment cost and energy savings [24]. In order to learn more about the gap between current design practice and climate adaptive design, a demonstration project was carried out together with a local developer with the objective to improve standard designs by applying various measures [25]. The building is located in Abuja Federal Capital Territory.

\section{METHODOLOGY > EFFICIENT AND SUSTAINABLE BUILDING DESIGN}

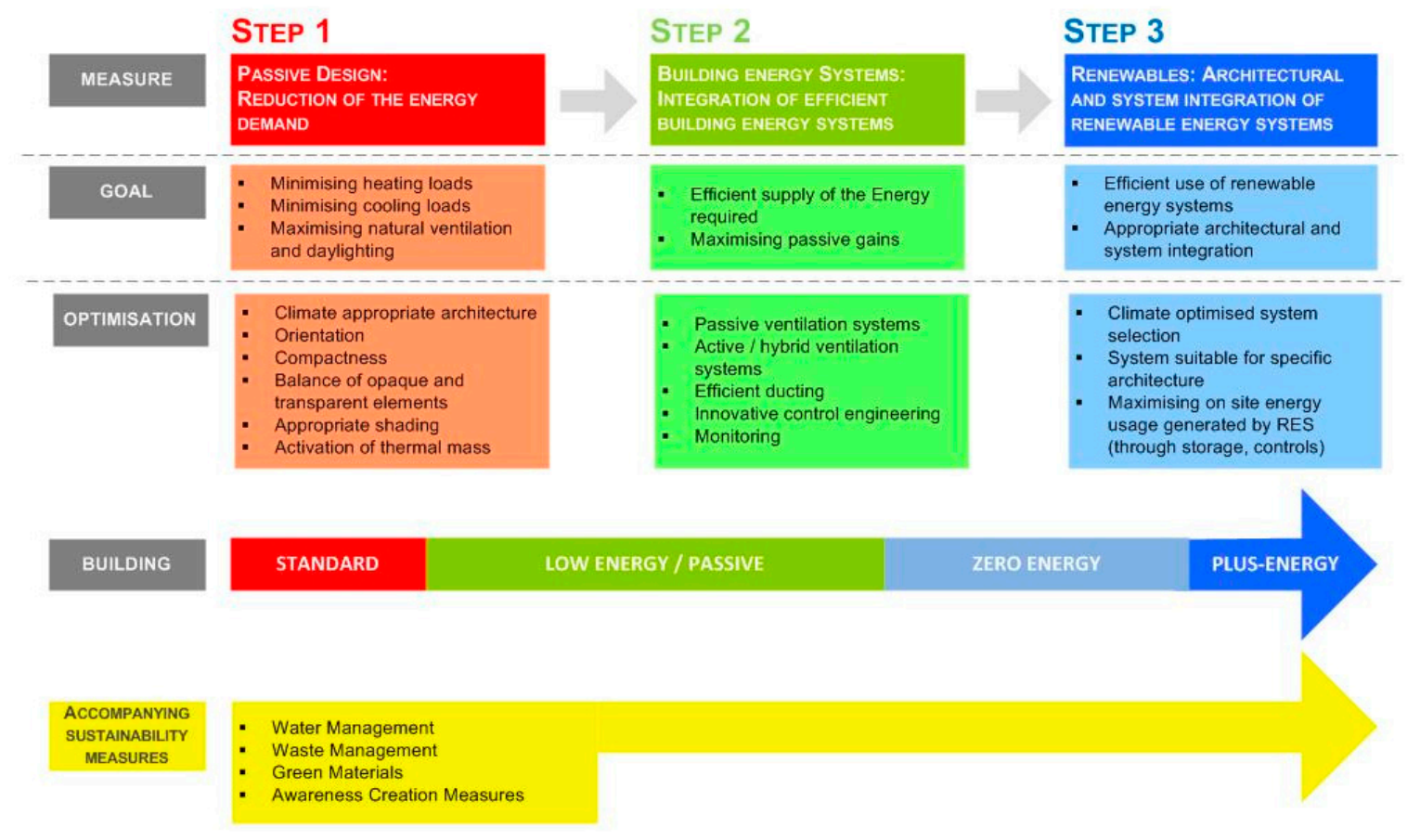

Figure 2. Methodology towards efficient and sustainable building design (Translated from [26]).

In order to demonstrate how climate adaptive design could be implemented in standard, local working procedures and design in Nigeria, a pilot project was set up for a typical multi-unit residential building. The goal of the project was to provide a showcase of energy-efficient design by delivering two almost identical buildings on one site to allow for a tangible and unique comparison in terms of design procedure, cost, and energy savings.

For this purpose on a site in the North of Abuja, two building blocks were planned for construction, one a 'Business as usual building' (BAU) representing the typical design and construction method, the other a 'Green Building' (GB) which would feature higher energy efficiency standards and include renewable energy systems. Both buildings were equal in terms of size and number of flats; they differed however in terms of the building specification, compactness, material properties, shading, and HVAC systems, as further described below. 
The detailed objectives of the development of the pilot project have been summarized as follows:

- Work closely with the local stakeholders to provide a knowledge base and sound methodology for energy-efficient design to those involved in planning and constructing the building.

- Consider local climate, resources, and design procedures in order to allow for a high replication potential.

- Define different scenarios for the energy-efficient design, which should vary in cost, complexity and reduction in energy demand. Compare the 'Business as usual' design with the developed scenarios.

- Select the most appropriate energy-efficient design to be constructed together with the 'Business as usual' design.

The procedure was to first assess the 'Business as usual' (BAU) design provided by the local planners in order to quantify energy consumption and $\mathrm{CO}_{2}$ emissions. Based on the BAU design, four scenarios which varied in terms of energy efficiency, implementation of advanced building energy systems, and costs were developed in close collaboration with the local planning team to provide appropriate designs that were suitable for the local environment in terms of material and system availability, and local knowledge and skills, as well as local environmental and other framework conditions. The development of the scenarios followed the principal logic of sustainable design (see Figure 2), which had been elaborated with the local planning team. Each scenario consisted of various sets of measures. The BAU, as well as the four developed scenarios were subsequently analyzed in a detailed energy and cost assessment. After the finalization of the scenario development and analysis, one final design of the 'energy-efficient' building block (the 'Green Building' or GB as referred to below) was selected for construction.

The building site was located in the northern part of Abuja, Nigeria, in a (at the time of planning) still mostly undeveloped area. There was no significant shading by vegetation and there were only minor topographical changes within the site, meaning that the area where the buildings were to be erected was relatively flat. For the assessment, the following location data was used: Longitude: 9.07\% / Latitude: $7.39^{\circ}$ /Elevation above sea level: $476 \mathrm{~m}$. Local weather data for the project site was derived using the ClimateTool software [27]. The area around Abuja falls into tropical savannah climate with monthly mean temperatures ranging above $18{ }^{\circ} \mathrm{C}$, and distinct dry and wet seasons. The temperature in Abuja ranges from low $20^{\circ} \mathrm{C}$ up to $40{ }^{\circ} \mathrm{C}$ over $80 \%$ of the daytime, and $50 \%$ of the night-time temperatures range on or above $25^{\circ} \mathrm{C}$. Night cooling can be exploited if temperature differences between day and night are greater than $10 \mathrm{~K}$ and absolute humidity at the minimum night temperature is below $12 \mathrm{~g} / \mathrm{kg}$. For the selected location there would be a constant need for night cooling as temperatures during the day generally exceed $21^{\circ} \mathrm{C}$, but the relatively small difference between night and day temperatures and relatively high humidity levels during the night mostly prevented night cooling. Yearly total irradiation (horizontal) is with $1800 \mathrm{kWh} / \mathrm{m}^{2}$ a relatively high, thus solar potential could be used for the application of renewable energy systems.

As described above, two building blocks were planned for construction on the selected site. Both buildings consisted of three flats over two floors featuring the same size as well as number of flats and rooms. Layout and sizes of units within the two buildings were (apart from some minor details) the same. Each flat was approximately $140 \mathrm{~m}^{2}$ and consists of a living or dining room and kitchen on the ground floor, as well as two bedrooms with walk-in closets and bathrooms on the first floor. The BAU design was defined as a building that represented commonly built practice by the local planning team. The built-up form of the external envelope as well as the building system reflected standard specifications as applied throughout numerous projects carried out by the involved participants. The set-point temperature for heating was defined as $20^{\circ} \mathrm{C}$ and for cooling as $25^{\circ} \mathrm{C}$. The domestic hot water (DHW) demand was calculated as $30 \mathrm{~L} /$ person/day. The main building properties have been summarized in Table 1 as follows: 
Table 1. Building properties of the case study.

\begin{tabular}{ccc}
\hline Component & U-Value & Description \\
\hline External Walls & $2.18 \mathrm{~W} /\left(\mathrm{m}^{2} \mathrm{~K}\right)$ & 200 mm brick wall with plaster on each side \\
Roof & $2.22 \mathrm{~W} /\left(\mathrm{m}^{2} \mathrm{~K}\right)$ & plasterboard ceiling, wood trusses with aluminum sheeting \\
Floor & $1.4 \mathrm{~W} /\left(\mathrm{m}^{2} \mathrm{~K}\right)$ & tile floor, screed, concrete floor slab \\
Windows & $5.8 \mathrm{~W} /\left(\mathrm{m}^{2} \mathrm{~K}\right)$ & g-Value: 83\%, single glazing; no shading \\
\hline HVAC System & Domestic Hot Water by individual electrical heaters; cooling/ventilation with \\
& & de-centralized split AC units (COP 3) \\
\hline
\end{tabular}

In the first stage, a detailed energy and cost assessment was undertaken on the BAU design. The energy analysis was carried out using the software package PHPP Version 9 [28]. The package was chosen as it provides low cost and is an easy to learn alternative compared to more complex and/or more expensive simulation tools such as EnergyPlus [29] or TRNSYS [30]. The requirement was that the chosen simulation tool could be applied in the training sessions with local planners and stakeholders, and would allow the tool to be used with relatively limited amounts of training and simulation knowledge. The tool is based on Excel and SketchUp [31], which have been considered to be most widely available and known by the local planners. The analysis provided by the tool included heating and cooling demands $\left[\mathrm{kWh} /\left(\mathrm{m}^{2} \mathrm{a}\right)\right]$, maximum heating and cooling loads $\left[\mathrm{W} / \mathrm{m}^{2}\right]$, frequency of overheating [\%], and primary energy demand. The tool allows variations in the building design as well as the building energy system. By choosing this simplified method, it was accepted that the results could not be as detailed as compared to simulations carried out with a thermal dynamic simulation tool. Nevertheless the results should provide meaningful comparative answers to the different measures applied in the scenarios.

The cost assessments were carried out based on cost data delivered by the local quantity surveyor and architects. Electricity costs were calculated with 20 NGN/kWh. Since the BAU design did not consider orientation, compactness of the building shape, or shading, the calculated cooling load was excessively high, as it was generally accepted practice that the air conditioning system would provide a comfortable indoor environment regardless of the buildings' architecture.

In the second stage, various scenarios were developed together with the local planning team. The objective was to provide variations ranging from no-cost scenarios with reasonable improvements, up to high-cost scenarios and very complex systems. The latter might have not been considered for this pilot project, but was considered important to serve as examples for future projects. The results are discussed in the following Section 3.

\subsection{Development of the Nigerian Building Energy Efficiency Code}

\subsubsection{Criteria for BEEC Development}

The specification for developing the BEEC was based on the lessons learnt during the preparation work. It was agreed that the development of energy efficiency requirements must certainly meet the following requirements already documented by the BEEG:

- To fully exploit the potential of climate adaptive design as the most cost-effective energy efficiency measure;

- To consider the actual availability of energy-efficient products;

- To avoid or at least limit additional investment cost due to the need to make use of specific materials;

- To take into account the current qualification level of professionals and authority personnel, because professionals will have to comply with requirements, and authority personnel will have to check compliance. 
In addition, the structure of the three-step approach shown below should be followed in order to achieve good compliance and thus actual energy efficiency [32]:

- There should be clear procedures on how energy performance is determined (procedures address qualified experts).

- There should be clear procedures on how to decide on non-compliance and related actions (procedures for design approval and permit issue by officials).

- There should be effective control and sanctioning mechanisms to be applied in cases of non-compliance (procedures to explain what will happen if building designs and the as-built situation do not comply).

Because of the expected rapid increase in electricity consumption and limited generation capacity lagging far behind demand, actual energy efficiency is paramount. Consequently, energy efficiency requirements should clearly refer to the completed building and not only to the building design.

Overall, the BEEC should be effective but simple, and easily understood not only by professionals but also by the general public in order to contribute to creating widespread awareness and acceptance of energy efficiency in buildings.

\subsubsection{Procedure for BEEC Development}

Development of the technical BEEC document started in September 2016 in cooperation with the Federal Ministry of Power, Works and Housing (Housing Sector), and with the Department of Development Control (AMMC) Federal Capital Territory Administration Abuja. While the Federal Code can be directly applied for the Ministry's own buildings, it must be adopted and implemented as a building regulation on the state level in order to be mandatory for all other buildings. In terms of building regulation, Abuja Federal Capital Territory (FCT) is treated like the 36 Nigerian States. For this reason, development of the BEEC in collaboration with the Department of Development Control Abuja, representing the building authority in charge of building permit approval and checking compliance, should demonstrate the feasibility and benefits of BEEC application, and thus serve as a role model for applying the BEEC at state level throughout Nigeria.

The definition of energy efficiency minimum requirements was based on a parametric study carried out by a group of consultants in close collaboration with the Department of Development Control Abuja. In the initial stage of BEEC development, the scope of energy efficiency minimum requirements covered two building categories, namely residential and office buildings [33].

A number of actually submitted designs were analyzed, and the procedure of building permit approval was studied. Based on these studies of design documentation for planned building projects and expert opinions, the Nigerian Building Energy Efficiency Guideline (BEEG) and the pilot project described in the previous chapters, common design and construction practices were identified. Through modeling and simulations of a defined "standard" building (the BAU model) taking into account the various climatic conditions found in Nigeria, the expected energy performance was determined. Further, through review of international references as well as simulation of variations of the BAU model, the minimum energy efficiency requirements were identified that led to a minimum of $40 \%$ energy savings over current building practices [33].

When defining the minimum requirements, it was crucial to strike a balance between modest energy efficiency minimum requirements in terms of causing additional investment cost that society would accept, and the fact that energy efficiency minimum requirements must be sufficiently ambitious to qualify buildings to be compliant with the code for financing with new financing instruments. For example, the Climate Bond initiative demands energy savings of at least $40 \%$ over current building practices in the residential sector to be eligible for finance trough climate bonds [34].

Several financing mechanisms require annual investor disclosure regarding achieved energy savings. Although simplified procedures are applicable for the residential sector, it is paramount that 
planned energy savings are achieved in practice in order to build public trust in the effectiveness of energy efficiency measures.

In this regard, it is evident that the BEEC would only be effective if regularly controlled. Therefore, energy efficiency minimum requirements were defined in a way that allows for double checking during the design stage and after completion. For checking building design, easy-to-use tools were developed so that supporting documents could be submitted together with the other material necessary for building permit application.

A very important part of the project was to offer training for staff of the Development Control involved in checking building documents and completed buildings, and issuing permits, to enable them to check also whether energy efficiency minimum requirements were met. Integrating energy efficiency compliance checks in the daily routine of the Development Control Department was the key to the success of the BEEC in the Nigerian Environment, and thus also dominated the definition of energy minimum requirements: only such energy efficiency minimum requirements are part of the BEEC which can be checked, and checking is an integral part of the Code [33].

\section{Results}

\subsection{Results of Preparatory Activity 1: Nigerian Building Energy Efficiency Guideline (BEEG)}

The first Nigerian Building Energy Efficiency Guideline (BEEG) was developed to address the severe lack of awareness regarding energy efficiency in buildings in the professional environment.

The Federal Ministry of Power, Works and Housing officially launched the Guideline in June 2016. It includes all relevant aspects for delivering affordable energy-efficient buildings in practice, in order to provide information to developers, architects and engineers, construction companies, material and equipment providers, and authorities. It was not the intention to cover the entire matter fully, but to touch upon the most relevant issues in order to create awareness and to prepare stakeholders for the development of the Nigerian Building Energy Efficiency Code (BEEC). It was not the intention either, to develop a training book, although the Guideline can be used as a starting point for developing training material.

The table of content and a short explanation is shown in Table 2 below.

Table 2. BEEG table of contents [24].

\begin{tabular}{|c|c|}
\hline Table of Contents & Short Description of the Contents \\
\hline $\begin{array}{l}\text { 1. Introduction to energy efficiency in buildings } \\
\text { 2. Integrated design process: the process of planning } \\
\text { an energy-efficient building } \\
\text { 3. Energy objectives in the building sector of Nigeria } \\
\text { 4. Bioclimatic building design: concepts } \\
\text { 5. Bioclimatic architecture in Nigeria } \\
\text { 6. Active systems } \\
\text { 7. Renewable energy technologies } \\
\text { 8. Regional hazards affecting building and } \\
\text { 9. Tystems design } \\
\text { 10. Regulatory framework } \\
\text { 11. Sustainability certification } \\
\text { 12. Case studies: energy analysis of buildings in Nigeria }\end{array}$ & $\begin{array}{l}\text { The Guideline provides a general introduction to energy } \\
\text { efficiency in buildings, and presents the integrated design } \\
\text { procedure as the appropriate method to deliver } \\
\text { energy-efficient buildings. Climate adaptive design, called } \\
\text { Bioclimatic design in the Nigerian context, is identified as } \\
\text { essential in order to improve energy efficiency at no or low } \\
\text { additional cost. Passive and active energy efficiency } \\
\text { measures are presented as well as renewable energy systems } \\
\text { suitable for building integration. The Guideline also includes } \\
\text { a description of natural hazards and an assessment of } \\
\text { building energy simulation and calculation tools, as well as } \\
\text { whole building design tools and sustainability certification } \\
\text { models used globally. The regulatory framework necessary } \\
\text { for the implementation of building energy efficiency in } \\
\text { Nigeria is presented, and already contains those elements to } \\
\text { be tackled by the Nigerian Building Energy Efficiency Code } \\
\text { to come. This procedure should promote societal support for } \\
\text { future energy efficiency legislation. }\end{array}$ \\
\hline
\end{tabular}

Discussions about construction methods, availability of energy-efficient products, and qualification levels of the average professionals showed that currently, options for improving energy efficiency were very limited, especially when having in mind that mass housing must be targeted. In this regard, energy efficiency requirements had to be widely applicable and cause either no or only very low additional 
cost. Otherwise, societal support will be denied and requirements will not be respected. This is the reason why the Guideline promotes the objective of climate adaptive design strategies for Nigeria, in order to minimize heat gains and to promote heat loss by means of building orientation facing mainly north and south with overhangs or external shading, as these are the most cost effective measures in terms of energy efficiency.

\subsection{Results of Preparatory Activity 2: Case Study Building Analysis}

Based on the methodology outlined in Section 2.2, Figure 3 provides an overview of the scenarios and the individual measures, which were considered in each scenario as well as the comparative results. It showed that the development of the scenarios followed the basic principle of sustainable design as described in Figure 2: In the first steps, the passive design measures were exploited (Scenarios 1 and 2). Based on the improvements of the building shell and energy relevant architectural aspects, the building energy system measures were adapted. Building on an already energy-efficient design in terms of architecture and building systems, the renewable energy measures were included in the last scenarios (Scenarios 3 and 4). The GB scenario reflected the measures, which were finally selected by the planning team to be implemented in the constructed building in comparison with the BAU building.

\begin{tabular}{|c|c|c|c|c|c|c|c|c|}
\hline Subject & Data Description & Unit & BAU & $\begin{array}{c}\text { Scenario } \\
1\end{array}$ & $\begin{array}{c}\text { Scenario } \\
2\end{array}$ & GB & \begin{tabular}{|c} 
Scenario \\
3
\end{tabular} & $\begin{array}{c}\text { Scenario } \\
4\end{array}$ \\
\hline \multirow{11}{*}{$\begin{array}{l}\text { MEASURES } \\
\text { Changes to } \\
\text { Business as } \\
\text { Usual (BAU) }\end{array}$} & Adapted Building Shape & & & $\mathrm{x}$ & $\mathrm{x}$ & $\mathrm{x}$ & $\mathrm{x}$ & $\mathrm{x}$ \\
\hline & Solar Shading, adapted Window Height & & & $\mathrm{x}$ & $\mathrm{x}$ & $\mathrm{x}$ & $\mathrm{x}$ & $\mathrm{x}$ \\
\hline & Film on Single Glazing & & & $\mathrm{x}$ & & $\mathrm{x}$ & & \\
\hline & Improved Building Shell High Performance & & & & $\mathrm{x}$ & & $\mathrm{x}$ & $\mathrm{x}$ \\
\hline & Improved Building Shell Low Performance & & & & & $\mathrm{x}$ & & \\
\hline & Higher efficiency on split units & & & & & $\mathrm{x}$ & $\mathrm{x}$ & \\
\hline & Solar thermal for domestic hot water preparation & & & & & $\mathrm{x}$ & $\mathrm{x}$ & $\mathrm{x}$ \\
\hline & Photovoltaic & & & & & $\mathrm{x}$ & $\mathrm{x}$ & $\mathrm{x}$ \\
\hline & Central Ventilation System & & & & & & & $\mathrm{x}$ \\
\hline & Concrete Core Activation & & & & & & & $\mathrm{x}$ \\
\hline & Central adsorption cooling system with solar thermal & & & & & & & $\mathrm{x}$ \\
\hline \multirow{5}{*}{$\begin{array}{l}\text { Changes to } \\
\text { BAU in \% }\end{array}$} & Cooling demand reduction compared to BAU & $\%$ & & $20 \%$ & $44 \%$ & $23 \%$ & $44 \%$ & $44 \%$ \\
\hline & Electrical demand reduction compared to BAU & $\%$ & & $14 \%$ & $32 \%$ & $75 \%$ & $83 \%$ & $100 \%$ \\
\hline & $\mathrm{CO}_{2}$ Emissions reduction compared to $\mathrm{BAU}$ & $\%$ & & $14 \%$ & $32 \%$ & $75 \%$ & $83 \%$ & $100 \%$ \\
\hline & $\begin{array}{l}\text { Total yearly electrical energy costs reduction } \\
\text { compared to BAU }\end{array}$ & $\%$ & & $14 \%$ & $32 \%$ & $75 \%$ & $83 \%$ & $100 \%$ \\
\hline & Additional Investment Costs & $\%$ & & $3.7 \%$ & $10.0 \%$ & $7.6 \%$ & $14.5 \%$ & \\
\hline
\end{tabular}

Figure 3. Comparative results for Business as Usual (BAU) design, Green Building (GB), and scenarios [21].

The scenarios were improved with each step and thus built mostly upon the measures of the respective previous scenarios. In short the scenarios can be summarized as follows (see Figure 3):

- Scenario 1: simple and highly cost-effective passive design measures (increased compactness; reflective coating on glazing, solar shading). Material changes compared to BAU: U-Value windows $\left(4.0 \mathrm{~W} / \mathrm{m}^{2} \mathrm{~K}\right)$; g-value windows $(70 \%)$.

- Scenario 2: advanced passive design measures by means of an improved high performance building shell (as Scenario 1 but with improved thermal properties of the building envelope). Material changes compared to BAU: U-value windows $\left(3.1 \mathrm{~W} / \mathrm{m}^{2} \mathrm{~K}\right)$; g-value windows $(70 \%)$; U-value external walls $\left(0.34 \mathrm{~W} / \mathrm{m}^{2} \mathrm{~K}\right)$; U-value roof $\left(0.33 \mathrm{~W} / \mathrm{m}^{2} \mathrm{~K}\right)$, U-value floor $\left(0.32 \mathrm{~W} / \mathrm{m}^{2} \mathrm{~K}\right)$.

- GB Scenario: reflects the measures as agreed with the local planning team for construction; lower performance of the building shell compared to Scenario 2, but higher compared to BAU (passive design measures); improved building systems and implementation of renewable 
energy systems. Material changes compared to BAU: U-value windows $\left(4.0 \mathrm{~W} / \mathrm{m}^{2} \mathrm{~K}\right)$; g-value windows $(70 \%)$; U-value external walls $\left(1.8 \mathrm{~W} / \mathrm{m}^{2} \mathrm{~K}\right)$; U-value roof $\left(2.0 \mathrm{~W} / \mathrm{m}^{2} \mathrm{~K}\right)$, U-value floor $\left(1.4 \mathrm{~W} / \mathrm{m}^{2} \mathrm{~K}\right)$. Building system changes compared to BAU: air conditioning (AC) units with a COP 3.5; Solar Thermal efficiency factor: $70 \%$; Photovoltaic (PV) efficiency factor: $20 \%$

- Scenario 3: describes the next step up from Scenario 2 as originally foreseen for implementation, and includes improved building systems and implementation of renewable energy systems; the GB is basically a slightly tuned down (and more cost-effective) version than Scenario 3. Material changes compared to BAU are as in Scenario 2. Building system changes compared to BAU are as in the GB Scenario.

- Scenario 4: shows what could be done in the future and reflects a highly advanced level of design involving passive as well as active measures. Material changes compared to BAU are as in Scenario 2 . The building systems in this scenario are relatively complex and cost intensive due to a separate cooling and ventilation system as well as the increased use of renewable energy. The system comprises of a central adsorption solar cooling system with concrete core activation (radiative cooling) and ventilation system; the PV system covers the night-time use of the central cooling and ventilation unit and 100\% use of lighting and small power (with batteries or grid connection). Building system changes compared to BAU: Adsorption cooling efficiency factor $70 \%$; solar thermal efficiency factor: $70 \%$; PV efficiency factor: $20 \%$.

\subsubsection{Comparison of Scenarios}

The results showed that the cooling demand was most greatly reduced by advanced passive design measures (as used in Scenarios 2-4). As the overall system was only based on electricity as an energy carrier, $\mathrm{CO}_{2}$ emissions and energy costs were most highly reduced in those scenarios where renewable energy systems were applied (Scenario GB, 3 and 4). However, even with relatively simple and cost effective measures such as film on glazing and shading on all windows (Scenario 1), a cooling energy reduction of $20 \%$ could be achieved. In the GB Scenario, the walls were in addition slightly improved, bringing the cooling demand reduction compared to BAU, to $23 \%$. Adding in renewable energy provision, the overall reduction of electricity from the grid or private diesel generators in Scenario GB was $75 \%$ compared to BAU. In Scenarios 3 and 4, the effect of the high performance building shell could be seen in the even further reduced cooling demand, which came down to $44 \%$ compared to BAU. In Scenario 4 , the reduction for electrical demand, $\mathrm{CO}_{2}$, and yearly energy costs was $100 \%$ as the building was theoretically $100 \%$ self-sufficient and would have (with adequate batteries or load shifting to and from the grid) not needed any energy from external non-renewable sources. It must be noted that Scenario 4 was at the time of the study not a feasible option for Nigeria as neither the companies to be used for planning and installing the system, nor for providing adequate maintenance, were locally available. Therefore, it was also not possible to gather any meaningful cost data on these systems. Nevertheless, during the workshops with the local planning team it was decided that this scenario would be included in the options, to highlight which systems could be adequate for the climate and could potentially be implemented in the future.

Figure 4 depicts the total annual electrical energy demand (above zero) and electrical generation by PV (below zero, shown in green). The GB Scenario already showed a relatively high share of renewable energy systems; however the cooling demand side (blue) was still higher than Scenarios 2-4 as the building shell was only moderately improved. In Scenarios GB, 3, and 4, the power demand for lighting and small power (yellow) was also reduced due to LED (light-emitting diode) lighting. In the scenarios GB, 3, and 4 there was no electrical demand from DHW (domestic hot water) as these scenarios included the measure "solar thermal for domestic hot water preparation". Thus in these scenarios, DHW was entirely covered by the solar thermal system with subsequently no additional electrical demand. 


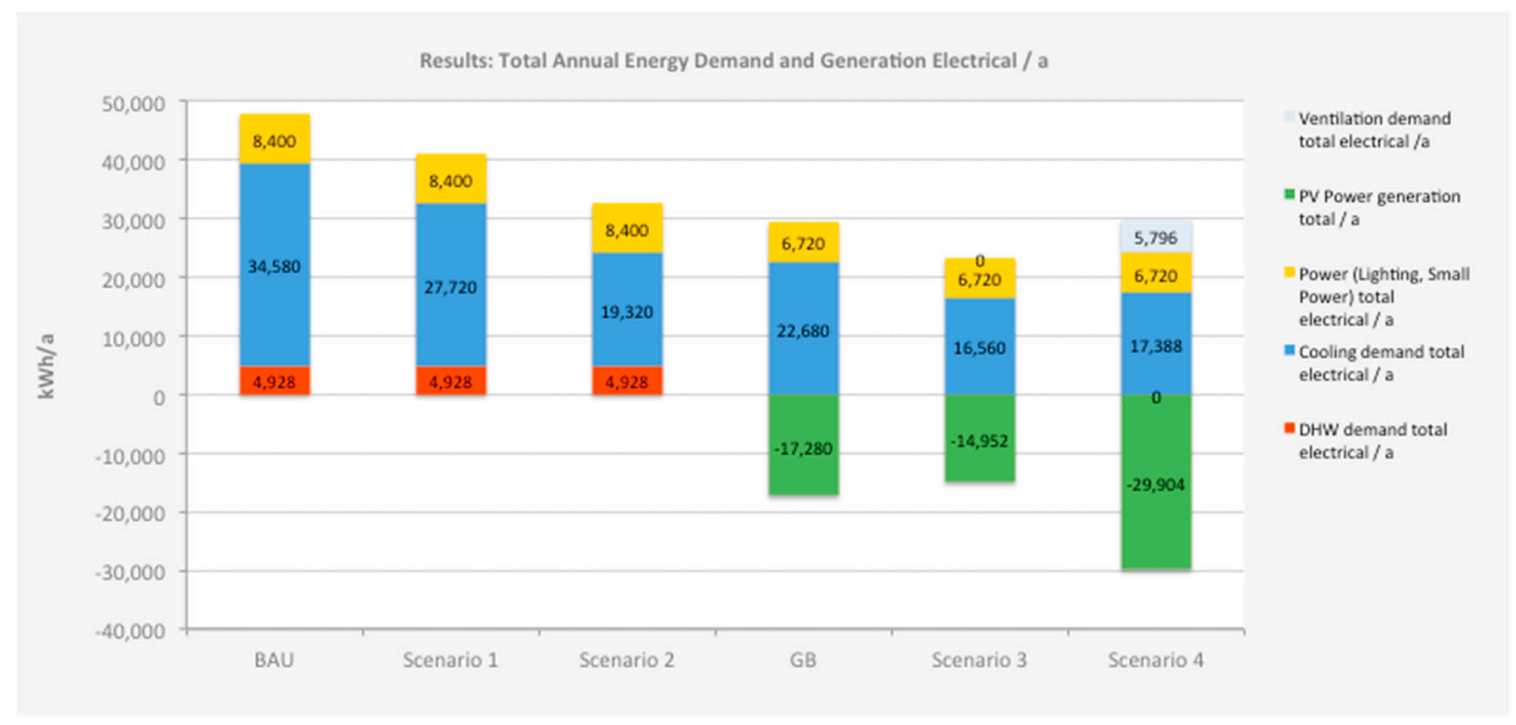

Figure 4. Total annual energy demand and generation per year [21].

Overall, the selected GB Scenario allowed for an effective compromise between additional investment costs and resulting energy savings. The GB Scenario would thus provide an advanced showcase on how energy and resulting $\mathrm{CO}_{2}$ emissions can be saved with relatively simple and cost-effective measures. This scenario has been put forward for planning approval in summer 2016 and subsequent construction. It will be built together with the BAU building block on the above-described site as a pilot project. It was further planned, that the energy consumption of building blocks would be monitored to allow for a direct comparison of the buildings on use.

\subsubsection{Lessons Learned from the Case Study}

At the time of submitting this paper, planning approval was not yet given. The developer faced twofold challenges: first, there were unexpected changes in the design team, seriously affecting the work, and second, there was a dramatic currency decline in 2016, impacting negatively on the Nigerian economy in general and also delaying the demonstration project described above. Nevertheless, three important conclusions were drawn from the analysis of the pilot project:

- Training offers for the building authority are of utmost importance.

- The approach chosen in Scenario 1 could be used as a basis for developing mandatory criteria stipulated by the Nigerian Building Energy Efficiency Code as additional costs are low and within a range that is considered to be socially acceptable.

- Other energy simulation tools than PHPP should be investigated for roll-out because certain limitations have been encountered using the PHPP tool with the Abuja climate. Although the PHPP version used in the project was adapted for application in tropical climates, it became evident that modifications were not sufficient to cope with the practical challenges met in regions with high cooling energy demand. The PHPP has been developed to carry out detailed energy calculations specifically for passive house designs, and the software is geared towards heating rather than cooling assessments. The identified disadvantages clearly outweigh the benefit of running the program on Microsoft Excel, which is widely available and easily accessible.

\subsection{Nigerian Building Energy Efficiency Code}

The BEEC consists of the following elements [35]

- Minimum energy efficiency requirements and verification methods;

- Calculation methods and tools; 
- Building energy label and energy efficiency incentives;

- Control and enforcement;

- Qualification of experts;

- Review and adaptation.

The BEEC applies to new buildings only, and those that fit into the building classifications according to National Building Code, referring to spaces used primarily for office work and residential buildings. For residential buildings, a minimum threshold of $85 \mathrm{~m}^{2}$ gross floor area applies to a standalone building.

The provisions of the BEEC apply directly to the Public buildings of the Ministry responsible for the National Building Energy Efficiency Code. In addition, the BEEC shall be adopted by the States and Local Governments in order to apply the provisions to all relevant matters within their responsibility. After adoption, the BEEC is voluntary for up to a maximum of two years, to allow for an adoption and inception phase. After this period, the competent authority shall then make all BEEC requirements mandatory.

Minimum energy efficiency requirements apply to all climatic zones in Nigeria.

Energy efficiency interventions are specified based on bioclimatic (climate adaptive) principles described in the National Building Energy Efficiency Guideline (BEEG), and include:

- Reduction of overall Window-to-Wall Ratio or implementation of shading: Window-to-Wall Ratio for any orientation shall not exceed $20 \%$. Where the design is such that this cannot be achieved, then all glazing elements on the relevant facades are to be adequately shaded.

- Reduction of installed lighting power density: Lighting power density shall not exceed $6 \mathrm{~W} / \mathrm{m}^{2}$ for residential buildings and $8 \mathrm{~W} / \mathrm{m}^{2}$ for office buildings. Calculations are to be carried out over the gross floor area of a building. Installed power and energy consumption of artificial lighting should be minimized by the use of more efficient lamp/ballast systems and luminaires. The requirements include ballast losses.

- Minimum requirements for roof insulation: All roof constructions are to include a layer of insulation with thermal resistance not less than $1.25 \mathrm{~m}^{2} \mathrm{~K} / \mathrm{W}$ (R-value).

- Minimum performance of air conditioning equipment specified: All air-conditioning units shall have a minimum EER/COP (Energy Efficiency Ratio/Coefficient of Performance) of 2.8 and shall be of the inverter type. Only air conditioners with inverters shall be accepted for installation in buildings.

Minimum energy efficiency requirements do not include energy consumption due to appliances for offices and households, related to industrial or other processes, and for heating water.

The BEEC does not only prescribe energy efficiency minimum requirements, but also prescribes the two methods of demonstrating compliance:

- Compliance Method 1 Prescriptive approach: For this option, building projects must adhere to all the requirements as a checklist.

- Compliance Method 2 Performance approach: Project teams may deviate from the prescriptive requirements, provided that the theoretical energy use of the building is less than or equal to that of the same building with all the prescriptive requirements included. A whole building analysis using energy simulation software must be carried out. Documents must be submitted according to the BEEC Modeling Protocol, which also contains the outline of the BEEC Modeling Report. Simulation software packages used for demonstrating compliance with Compliance Method 2 shall be certified for energy modeling by at least one of the following organizations or equivalent: ASHRAE (American Society of Heating, Refrigerating and Air-Conditioning Engineers), IECC (International Energy Conservation Code). 
The BEEC stipulates that verification documents for demonstrating compliance shall be submitted to the competent authority two times; (1) prior to obtaining the Building Permit; and (2) prior to obtaining the Certificate of Use and Habitation.

There are provisions for checking compliance and how to react in the case of non-compliance: Energy Efficiency Inspectors with defined qualifications shall physically check that measures, products, and systems have been installed in accordance to the submitted verification documents (spot check, sampling size 5\%). It is important to note that appraisals and site checks of completed buildings shall be undertaken in-house by the competent authority and shall not be outsourced. The BEEC stipulates that buildings not complying after completion shall be rated as BEEC non-compliant and the result of the rating shall be publicized.

\section{Discussion}

With more than 190 million inhabitants, more than 400 ethnic groups, a major share of uneducated jobless youth, persistent violent conflicts on natural resources, and an economy nearly fully dependent on crude oil export, it is clear that Nigeria is a difficult terrain to work on energy efficiency in buildings [10,36,37]. However, there are also extremely interested and motivated groups working on improving the situation, especially in the energy field, because it is evident that insufficient electricity availability hampers the economic development of the country. In general, the work done to develop the BEEC could be criticized as being selective and thus less effective, and in particular the foundation regarding building and energy data as not being sufficient to build upon. However, at the beginning of the project, it was agreed on how to deal with the persistent lack of data. Instead of performing an expensive one-time building data collection, it was decided to follow a case-based approach based on expert knowledge, and to use this approach for stakeholder involvement at the same time. Expectations have been high to achieve results because of the immense pressure on the electricity system and the related challenges. Therefore, methodological simplifications have been accepted consciously where justifiable, and focus has been put on the implementation and enforcement aspect of the energy efficiency building code, in order to activate real improvements in energy efficiency in buildings on the real estate market.

When pointing out the success factors of BEEC development, the importance of stakeholder engagement cannot be overemphasized. It is paramount for developing feasible solutions accepted by stakeholders and thus is being consolidated by societal support. This project has benefitted enormously from teaming up with motivated stakeholders who are multipliers at the same time.

Although it has not yet been possible to build the case study buildings, the case study analysis has been very useful when discussing building energy efficiency with architects, engineers, and builders. The case study analysis has been a key element in disseminating the BEEC as the collaboration with a committed Nigerian developer has demonstrated the practical relevance of this effort.

Last but not least, the critical role of developing tender specifications and selecting consultants has to be addressed when analyzing factors of success. Technical work for developing the BEEG, the review of designs in the demonstration project with the Nigerian developer, and the parametric study for determining energy minimum criteria and developing the labeling scheme for the BEEC was contracted out to consultants. Terms of reference were extensively discussed with the responsible department of the Federal Ministry of Power, Works, and Housing. Wherever possible, international consultants teamed up with Nigerian consultants. It was a key to success to combine good knowledge and realistic assessment of the situation on the ground with international up-to-date know-how. International key consultants were required to spend some time on site discussing with national experts and stakeholders, to make sure that they properly understood the actual challenges, and thus elaborate suggestions suitable for connecting with the status quo and containing potential for future improvements at the same time. 


\section{Conclusions}

The BEEC was developed in view of the need for societal support, which is crucial for the BEEC to become a widely accepted construction standard. Currently, mandatory BEEC requirements are limited to very few but feasible and accepted energy efficiency minimum requirements applicable throughout Nigeria. Due to comparably high investment cost, lack of qualified staff, and serious problems with product quality, application of renewable energy technologies is not yet among them, despite the urgent need to also increase generation capacity besides tapping the full potential of energy savings. However, mandatory BEEC requirements are complemented by a labeling scheme rewarding voluntary measures that go beyond mandatory stipulations, such as more ambitious energy efficiency standards than those prescribed by the BEEC, and using solar energy systems.

However, the code document also states that the BEEC must be evaluated and revised at regular intervals in order to respond to improved qualification of involved staff, better availability of construction products, and increased public awareness. In the future, application of solar energy systems could also become mandatory, provided that the necessary enabling environment exists.

For now, stakeholder groups have to be addressed with the following measures to support the effective implementation of the BEEC:

- Building developers have to understand what they demand from their design team, and therefore training for developers in regards to energy efficiency is as important as training for the building planners and engineers. Developers play an important role in increasing the wider acceptance of energy efficiency measures, thus adding to the replication factor.

- Architects, engineers, and builders need vocational training on energy efficiency, and their professional organizations should provide continuing education courses to their members together with training institutions. Professionals should receive a certification (ideally from an official body) according to their qualification and skills in energy efficiency in order to give them an edge on the market, and to promote energy efficiency in buildings.

- Material and equipment providers have to become familiar with delivering product-related key data needed for designing energy-efficient buildings and for implementing testing procedures, in accordance with the new requirements. Besides new obligations, there are also new chances for energy-efficient products, as the BEEC will create demand for such products.

- Construction companies must understand that the BEEC represents an advanced construction standard and limits employment opportunities for unskilled workers. General training workshops on energy efficiency in buildings, but also product-specific training in collaboration with material and equipment providers are essential.

Authorities should act as role models and apply the BEEC to their own buildings. Apart from their power as building owners, authorities are crucial factors in setting up the technical and administrative environment for the implementation of the BEEC, among others testing laboratories, a register of qualified experts, and electronic procedures to facilitate data collection on energy efficiency in buildings, and to make use of them for policy evaluation and policy development. Regular publication of good examples, showcasing energy-efficient buildings, for example in the course of competitions, is a good method to create awareness among the general public.

Author Contributions: Author S.G. mainly developed the concept for developing the Building Energy Efficiency Code (BEEC) and the Building Energy Efficiency Guidelines (BEEG). Author D.Ö. mainly developed the study related to the development and analysis of the case study and the climate adaptive design. Author E.M. was responsible for the overall project management of the Building Energy Efficiency aspects of the Nigerian Energy Support Program.

Funding: This specific research received no external funding.

Acknowledgments: The paper is based on projects funded under the framework of the Nigerian Energy Support Program (NESP), a five-year working program (2013-2018), implemented by Deutsche Gesellschaft für Internationale Zusammenarbeit (GIZ) GmbH in collaboration with the Federal Ministry of Power Works and Housing (FMPWH), and funded by the German Government and the European Union. 
Conflicts of Interest: The authors declare no conflict of interest. The founding sponsors did not influence the collection of the data, the analysis or the interpretation of the data and did not influence the results of the study.

\section{References}

1. GIZ NESP. Energy Efficiency in Buildings (EEB) in Selected Sub-Sectors of the Nigerian Building Sector: Development of Recommendations for Interventions to Promote Energy Efficiency in Buildings. Scoping Study Report Developed under the Framework of the Nigerian Energy Support Program (NESP). 2014. Available online: http:/ / www.energyplatformnigeria.com/index.php/library/energy-efficiency (accessed on 8 April 2018).

2. GIZ NESP. The Nigerian Energy Sector: An Overview with a Special Emphasis on Renewable Energy, Energy Efficiency and Rural Electrification, 2nd ed. June 2015. Available online: https://www. giz.de/en/downloads/giz2015-en-nigerian-energy-sector.pdf; Energy Platform Nigeria: http://www. energyplatformnigeria.com/index.php/overarching (accessed on 8 April 2018).

3. OPEC. Annual Statistical Bulletin 2017. Available online: http://www.opec.org/opec_web/flipbook/ ASB2017/ASB2017/assets/common/downloads/ASB2017_13062017.pdf (accessed on 10 May 2018).

4. Yusuf, M. An Analysis of the Impact of Oil Price Shocks on the Growth of the Nigerian Economy, 1970-2011. Afr. J. Bus. Manag. 2015, 9, 103-115.

5. Offiong, A.I.; Atsu, I.A.; Ajaude, E.; Ibor, B.I. The Impact of Oil Price Shocks on the Economic Growth and Development of Cross River State, Nigeria. Int. J. Financ. Res. 2016, 7. [CrossRef]

6. Rentschler, J. Incidence and impact: The regional variation of poverty effects due to fossil fuel subsidy reform. Energy Policy 2016, 96, 491-503. [CrossRef]

7. Todd, J.A.; Geissler, S. Regional and Cultural Issues in Environmental Performance Assessment for Buildings. Build. Res. Inf. Int. J. Res. Dev. Demonstr. Innov. 1999, 27, 247-256. [CrossRef]

8. Habitat, U.N.; Cities and Climate Change Initiative. Regional Roll-Out Strategy for Africa $2012-2021$. 2011. Available online: http:// mirror.unhabitat.org/list.asp?typeid=3\&catid=550\&RecsPerPage=ALL (accessed on 8 April 2018).

9. World Bank. Indicator Rural Population: World Bank Staff Estimates Based on United Nations, World Urbanization Prospects. 2016. Available online: http:/ / data.worldbank.org/indicator/SP.RUR.TOTL.ZS? end $=2015 \&$ locations $=$ NG\&page $=2 \&$ start $=1960 \& v i e w=$ chart (accessed on 8 April 2018).

10. DESA. World Population Prospects Key, Findings and Advance Tables; Revision, Working Paper No. ESA/P/WP/248; Department of Economic and Social Affairs of the United Nations Secretariat: New York, NY, USA, 2017.

11. IEA. Indicator kWh Electricity Consumption per Capita: Based on IEA data from IEA Statistics @ OECD/IEA. 2014. Available online: http://data.worldbank.org/indicator/EG.USE.ELEC.KH.PC?locations=NG; http:/ / www.iea.org/statistics/statisticssearch/report/?country=Nigeria\%20\&product=balances (accessed on 29 June 2018).

12. United Nations. Resolution Adopted by the General Assembly on 27 July 2012 [without Reference to a Main Committee (A/66/L.56)] 66/288; The Future We Want; United Nations: New York, NY, USA, 2012.

13. ECREEE. Supporting Energy Efficiency for Access in West Africa; SEEA-WA 129364-Energy Facility, FED 2009/240: Unpublished Concept Note and Regional Workshop on the Validation of the Framework Document of the ECOWAS Directive on Energy Efficiency in Buildings; ECREEE: Praia, Cape Verde, 2011-2015.

14. Laustsen, J. Energy Efficiency Requirements in Building Codes, Energy Efficiency Policies for New Buildings. IEA Information Paper. 2008. Available online: https://www.iea.org/publications/freepublications / (accessed on 8 April 2018).

15. Levine, M.; de la Rue de Can, S.; Zheng, N.; Williams, C.; Amann, J.; Staniaszek, D. Building Energy Efficiency: Best Practice Policies and Policy Packages; Lawrence Berkeley National Laboratory LBNL-6006E; 2012. Available online: https: / / eaei.lbl.gov/sites/all/files/GBPN_Final.Oct_.2012.pdf (accessed on 8 April 2018).

16. State of South Australia. Final Report on National Energy Efficient Building Project; Retrieved from Government of South Australia Department of State Development; 2014. Available online: http://www. statedevelopment.sa.gov.au/resources/energy-efficiency/national-energy-efficiency-building-project (accessed on 8 April 2018). 
17. CA EPBD. Reports on Outcomes 2011-2015. Retrieved from: CA EPBD Concerted Action Energy Performance of Buildings. 2015. Available online: http://www.epbd-ca.eu/ca-outcomes/2011-2015 (accessed on 8 April 2018).

18. QUALICHeCK. Guidelines and Fact Sheets on Better Quality and Compliance. 2017. Available online: http:/ / qualicheck-platform.eu/ (accessed on 8 April 2018).

19. Oliver, P. Encyclopedia of Vernacular Architecture of the World; Cambridge University Press: Cambridge, UK, 1997.

20. Zhai, Z.; Previtali, J.M. Ancient vernacular architecture: Characteristics categorization and energy performance evaluation. Energy Build. 2010, 42, 357-365. [CrossRef]

21. Loonen, R.C.G.M.; Trčka, M.; Cóstola, D.; Hensen, J.L.M. Climate adaptive building shells: State-of-the-art and future challenges. Renew. Sustain. Energy Rev. 2013, 25, 483-493. [CrossRef]

22. Schelbach, S. Developing a method to improve the energy efficiency of modern buildings by using traditional passive concepts of resource efficiency and climate adaptation. Int. J. Sustain. Dev. Plan. 2016, 11, 23-38. [CrossRef]

23. Rubel, F.; Kottek, M. Observed and projected climate shifts 1901-2100 depicted by world maps of the Köppen-Geiger climate classification. Meteorol. Z. 2010, 19, 135-141. [CrossRef]

24. FMPWH-NESP. Building Energy Efficiency Guideline for Nigeria (BEEG); Federal Ministry of Power, Works and Housing: Abuja, Nigeria, 2016. Available online: https:/ / energypedia.info/images/c/c7/Building_Energy_ Efficiency_Guideline_for_Nigeria_2016.pdf;http:/ / www.energyplatformnigeria.com/index.php/library / energy-efficiency (accessed on 8 April 2018).

25. Österreicher, D. Revision of Business as Usual Building Design in Terms of Energy Efficiency, Deliverable D2: Short Papers on BAU and four Scenarios; Unpublished Report Developed under the Framework of the Nigerian Energy Support Program (NESP); NESP: Abuja, Nigeria, 2016.

26. Österreicher, D. School Building Refurbishment, Investigation of Energy-Optimized Refurbishment Concepts in Connection with New Functional Requirements in Existing School Buildings. Ph.D. Thesis, University of Technology Vienna, Wien, Austria, 2015.

27. ClimateTool Computer Software. Available online: http://www.climate-tool.com/en/home.html (accessed on 10 May 2018).

28. PHPP Version 9 Computer Software. Available online: http://www.passivehouse.com (accessed on 10 May 2018).

29. EnergyPlus. Available online: https:/ / energyplus.net (accessed on 10 May 2018).

30. Trnsys. Available online: http:/ / www.trnsys.com (accessed on 10 May 2018).

31. SketchUp. Available online: http:/ / www.sketchup.com/de (accessed on 10 May 2018).

32. Durier, F.; Geissler, S.; Wouters, P. Source Book for Improved Compliance of Energy Performance Certificates (EPCs) of Buildings. 2016. Available online: http:/ / qualicheck-platform.eu/results/reports/ (accessed on 8 April 2018).

33. FMPWH. Technical Study: Development of the Nigerian Building Energy Efficiency Code (BEEC). 2017. Available online: http:/ / www.pwh.gov.ng/download/1510059611415.pdf (accessed on 8 April 2018).

34. Climate Bonds Initiative, n.d. Residential Property Climate Bonds Certification Methodology. Available online: http:/ / www.climatebonds.net/low-carbon-buildings-criteria (accessed on 8 April 2018).

35. FMPWH. National Building Energy Efficiency Code, 1st ed.; Federal Republic of Nigeria: Abuja, Nigeria, 2017. Available online: http:/ / www.pwh.gov.ng/download/15100511246229.pdf (accessed on 8 April 2018).

36. Falola, T.; Heaton, M.M. A History of Nigeria; Cambridge University Press: New York, NY, USA, 2008.

37. CBN. Analysis of Energy Market Conditions in Nigeria; Occasional Paper No. 55; Central Bank of Nigeria: Abuja, Nigeria, 2015.

(C) 2018 by the authors. Licensee MDPI, Basel, Switzerland. This article is an open access article distributed under the terms and conditions of the Creative Commons Attribution (CC BY) license (http://creativecommons.org/licenses/by/4.0/). 